\title{
IMPLEMENTAÇÃO DA EDUCAÇÃO REMOTA EM TEMPOS DE PANDEMIA: ANÁLISE DA EXPERIÊNCIA DO ESTADO DE MINAS GERAIS
}

\author{
LA IMPLEMENTACIÓN DE LA EDUCACIÓN REMOTA EN TIEMPOS \\ PANDÉMICOS: ANÁLISIS DE LA EXPERIENCIA DEL ESTADO DE MINAS GERAIS
}

\begin{abstract}
THE IMPLEMENTATION OF REMOTE EDUCATION IN PANDEMIC TIMES: ANAL YSING THE EXPERIENCE OF THE STATE OF MINAS GERAIS
\end{abstract}

\author{
Breynner Ricardo de OLIVEIRA ${ }^{1}$ \\ Ana Cristina Prado de OLIVEIRA ${ }^{2}$ \\ Gláucia Maria dos Santos JORGE ${ }^{3}$ \\ Jianne Ines Fialho COELHO ${ }^{4}$
}

RESUMO: O artigo analisa a implementação da educação remota na Rede Estadual de Minas Gerais por meio do "Regime de Estudo não Presencial" (REANP) em tempos de pandemia. A pesquisa se deu em três fases: levantamento dos marcos institucionais do programa; análise dos eixos de ação e dos comentários nos canais de comunicação disponibilizados pela Secretaria de Educação (SEE). Os dados foram organizados em sete dimensões: (1) o acesso ao programa; (2) a receptividade ao REANP; (3) percepções sobre o aplicativo e suas funcionalidades (4) questões associadas à tecnologia; (5) conteúdo; (6) adesão à educação remota e (7) conexão entre os eixos do REANP. Os dados mostram a dificuldade que a SEE tem enfrentado para criar vínculos e estratégias de adesão multinível entre os atores institucionais, os instrumentos, os processos, as tecnologias, os territórios e seus profissionais. Os dados indicam que a educação pública remota vincula e potencializa questões sociais e econômicas e que a SEE as minimizou em seu desenho, linearizando a oferta. Não foram encontradas ações ou estratégias destinadas aos alunos da educação especial, quilombola, indígena e de jovens e adultos. As percepções dos usuários apontam para duas questões: os riscos de a educação remota aprofundar as desigualdades sociais e educacionais e a adoção de estratégias de formação virtual, apoiadas pelas tecnologias, pós pandemia.

PALAVRAS-CHAVE: Educação remota. Implementação de políticas educacionais. Desigualdade educacional. Tecnologias. COVID-19 e pandemia.

\footnotetext{
${ }^{1}$ Universidade Federal de Ouro Preto (UFOP), Ouro Preto - MG - Brasil. Professor no Programa de PósGraduação em Educação. Doutorado em Educação (UFMG). ORCID: https://orcid.org/0000-0003-0956-4753. E-mail: breynner.oliveira@gmail.com

${ }^{2}$ Universidade Federal do Estado do Rio de Janeiro (UNIRIO), Rio de Janeiro - RJ - Brasil. Professora no Programa de Pós-Graduação em Educação (PPGEdu). Doutorado em Educação (PUC-Rio). ORCID: https://orcid.org/0000-0002-0367-6669. E-mail: ana.oliveira@unirio.br

3 Universidade Federal de Ouro Preto (UFOP), Ouro Preto - MG - Brasil. Professora Associada no Departamento de Educação e Tecnologias (DEETE). Doutorado em Educação (UFMG). ORCID: http://orcid.org/0000-0002-0026-4853.E-mail: glauciajorge@gmail.com

${ }^{4}$ Universidade Federal de Ouro Preto (UFOP), Mariana - MG - Brasil. Doutoranda no Programa de PósGraduação em Educação. ORCID: https://orcid.org/0000-0003-0657-4649. E-mail: jiannecoelho@gmail.com
}

RIAEE - Revista Ibero-Americana de Estudos em Educação, Araraquara, v. 16, n. 1, p. 84-106, jan./mar. 2021. e-ISSN: 1982-5587 DOI: https://doi.org/10.21723/riaee.v16i1.13928 
RESUMEN: El artículo analiza la implementación de la educación remota en la Red del Estado de Minas Gerais a través del Régimen de Estudio no Presencial (REANP) en tiempos de pandemia. La investigación se llevó a cabo en tres fases: encuesta de los marcos institucionales del programa; análisis de las líneas de acción y comentarios en los canales de comunicación proporcionados por la Secretaría de Educación (SEE). Los datos se organizaron en siete dimensiones: (1) acceso al programa; (2) receptividad a REANP; (3) percepciones sobre la aplicación y sus funcionalidades (4) problemas asociados con la tecnología; (5) contenido; (6) adherencia a la educación remota y (7) conexión entre los ejes REANP. Los datos muestran la dificultad que SEE ha enfrentado para crear vínculos multinivel y estrategias de adhesión entre actores institucionales, instrumentos, procesos, tecnologías, territorios y sus profesionales. Los datos señalan que la educación pública remota vincula y mejora los problemas sociales y económicos y que SEE los ha minimizado en su diseño, linealizando la oferta. No se encontraron acciones o estrategias para estudiantes de educación especial, quilombola, indígenas y jóvenes y adultos. Las percepciones de los usuarios señalan a dos cuestiones: los riesgos de la educación remota que profundizan las desigualdades sociales y educativas y la adopción de estrategias de capacitación virtual, respaldadas por tecnologías, después de la pandemia.

PALABRAS CLAVE: Educación remota. Implementación de políticas educativas. Desigualdad educativa. Tecnologías. COVID-19 y pandemia.

ABSTRACT: The article analyzes the implementation of remote education in the State Network of Minas Gerais through the Regime de Estudo não Presencial (REANP) in pandemic times. The research took place in three phases: a survey of the program's institutional frameworks; an analysis of the lines of action and comments in the communication channels provided by the Secretariat of Education (SEE). The data were organized into seven dimensions: (1) access to the program; (2) receptivity to REANP; (3) perceptions about the application and its functionalities (4) issues associated with the technology; (5) content; (6) adherence to remote education and (7) connection between the REANP axes. The data show the difficulty that SEE has faced in creating links and multilevel adhesion strategies between institutional actors, instruments, processes, technologies, territories, and their professionals. The data indicate that remote public education links and enhances social and economic issues and that SEE has minimized them in its design, linearizing the offer. No actions or strategies were found for students of special education, quilombola, indigenous and youth and adults. Users' perceptions point to two issues: the risks of remote education deepening social and educational inequalities and the adoption of virtual training strategies, supported by technologies, after the pandemic.

KEYWORDS: Remote education. Implementation of educational policies. Educational inequality. Technologies. COVID-19 and pandemic. 


\section{Introdução}

2020 começou com um surto de doença respiratória, declarado Emergência de Saúde Pública de Importância Internacional pela Organização Mundial de Saúde (OMS), ao final de janeiro. Em 11 de março, a OMS caracterizou como pandemia o quadro da disseminação comunitária da COVID-19 que já atingia todos os continentes. Para conter a doença e minimizar o número de mortes, foram recomendadas três ações básicas: isolamento e tratamento dos casos identificados, testes massivos e distanciamento social. O distanciamento social, adotado pela maior parte dos países, implicou no fechamento de espaços que reunissem muitas pessoas, incluindo as instituições escolares.

De acordo com a Organização das Nações Unidas para a Educação, Ciência e Cultura (UNESCO), a suspensão das aulas produziu efeitos importantes para os sistemas de ensino e para a vida de alunos e suas famílias, com consequências para o desempenho educacional dos diversos países. No dia 25 de maio de 2020, 1.186.161.728 estudantes haviam sido afetados (67.7\% do total de matrículas) e 146 países fecharam suas escolas (UNESCO, 2020).

No Brasil, o Parecer no. 5/2020 do Conselho Nacional de Educação (CNE), homologado pelo Ministério da Educação (MEC), suspende as aulas presenciais em todo o território nacional. Tal situação deverá seguir ritmos diferenciados nos estados e municípios, a depender da extensão e intensidade da contaminação pela COVID-19. Considerando a autonomia dos entes federados, o documento propõe que os gestores educacionais promovam iniciativas para minimizar os impactos das medidas de isolamento social na aprendizagem dos estudantes, entre elas “[...] a realização de atividades pedagógicas não presenciais enquanto persistirem restrições sanitárias, garantindo ainda os demais dias letivos mínimos anuais/semestrais previstos no decurso" (BRASIL, 2020, p. 6).

Como garantir que as iniciativas adotadas por cada rede educacional serão capazes de minimizar o impacto da falta de aulas presenciais por mais de três meses? E que serão acessíveis a todos os alunos, considerando a diversidade desse público? Segundo Gomes (2020), o desafio atual dos gestores dos sistemas de ensino é definir os encaminhamentos adequados para a educação básica em um contexto de calamidade sanitária, crise econômica e instabilidade política, onde a educação já vinha sofrendo dificuldades orçamentárias.

Uma série de políticas emergenciais têm sido implementadas nas redes estaduais e municipais de ensino para atender as necessidades dos alunos, sejam elas de aprendizagem, de segurança, de alimentação e de proteção social. De acordo com Madeira et al. (2020), o 
estudo sobre a implementação de políticas públicas em contextos de emergência torna-se ainda mais relevante para se compreender o alcance destas iniciativas, objeto desse artigo.

Ao analisar o processo de implementação da educação remota na Rede Estadual de Minas Gerais por meio do "Regime de Estudo não Presencial” (REANP), pretende-se, a partir do desenho do programa definido pela Secretaria Estadual de Educação (SEE) e da análise da percepção de seu público-alvo (alunos, famílias e professores), discutir a complexidade de sua operacionalização a partir de duas dimensões, interligadas: (1) as dificuldades de se implementar um programa emergencial que vincula, conforme Oliveira e Daroit (2020), distintos atores, territórios, sujeitos e tecnologias, em uma perspectiva multinível e (2) o aumento da desigualdade educacional no estado, agravada pela pandemia e pela dinâmica da implementação do programa.

De natureza exploratória, a pesquisa se deu em três fases: a primeira tratou do levantamento dos marcos legais e institucionais do programa; na segunda, o programa foi analisado a partir dos três eixos do programa: as videoaulas disponibilizadas no YouTube (Se Liga na Educação), o aplicativo (Conexão Escola) e os cadernos de estudo (Planos de Estudos Tutorados - PET). Na terceira fase analisamos os comentários realizados pela audiência (pais, alunos, professores e outros) nos canais de comunicação disponibilizados pela SEE nas plataformas do aplicativo e do Se liga na Educação. Os dados, coletados entre os dias 25 de maio e 30 de junho de 2020, foram organizados em sete dimensões: (1) o acesso ao programa; (2) a receptividade ao REANP; (3) percepções sobre o aplicativo e suas funcionalidades (4) questões associadas à tecnologia; (5) conteúdo; (6) adesão à educação remota (7) conexão entre os eixos do Programa.

O artigo está estruturado em quatro seções, além da introdução e das considerações finais. A primeira seção apresenta uma síntese dos estudos sobre a implementação de políticas públicas, associando os efeitos desses processos ao aumento das desigualdades educacionais, especialmente em um contexto emergencial. A partir de dados socioeconômicos e educacionais, a segunda seção caracteriza o estado de Minas Gerais, explicitando suas disparidades regionais. A fim de dimensionar a complexidade educacional mineira, a seção também traz dados sobre o sistema estadual de ensino. Na terceira seção, o desenho do programa é apresentado. A quinta seção traz a análise dos dados levantados, a partir das dimensões que foram definidas. 


\section{Implementação de Políticas Públicas em contexto emergencial}

Os estudos sobre as políticas públicas estão interessados em entender o caminho entre a formulação da política e sua "entrega" aos beneficiários - cidadãos a quem se destina. Tradicionalmente, considera-se como fases deste processo a agenda, a formulação, a implementação e a avaliação das políticas públicas. Ainda que este ciclo não seja rígido, ele é um importante instrumento analítico para se compreender os complexos processos decisórios envolvidos na efetivação de uma política (SOUZA, 2003; OLIVEIRA, 2019). Em relação à fase da implementação das políticas, Madeira et al. (2020) afirmam que entre a proposta, desenho e posterior implementação de políticas, o nível de profissionalização da burocracia determinará a qualidade com que os serviços públicos serão entregues para as pessoas.

Ao analisar esse processo no contexto das políticas educacionais e das instituições escolares, Oliveira (2019) afirma que a compreensão do processo de implementação implica conhecer e acompanhar a trajetória da política, seu arranjo institucional e os atores envolvidos nos diversos níveis, até o nível local, no território. Como a política educacional se materializa na escola, é no nível local que a atuação dos burocratas de nível de rua revela como a política acontece cotidianamente, considerando suas estratégias para a adequação e recontextualização. De acordo com Pires (2019), os estudos sobre a implementação têm trazido importante contribuição para a reflexão sobre os efeitos destas políticas. No caso das políticas educacionais, considerando uma agenda que defende a distribuição de uma escolaridade de "qualidade" para todos, o olhar para as dinâmicas de implementação colabora na compreensão sobre os resultados atingidos (ou não). Pires (2019, p. 19) destaca um “[...] um tipo especial de efeito não pretendido [...], o efeito social da implementação". Seguindo esta linha, alguns estudos têm buscado identificar mecanismos, situações e experiências ocorridas nos encontros entre os burocratas de nível de rua e o público nas dinâmicas de implementação das políticas. Estas relações poderiam, da forma como são estabelecidas, contribuir para a reprodução das desigualdades sociais.

Em se tratando da implementação de políticas educacionais, importa compreender como as distorções ou adaptações decorrentes das múltiplas ações dos implementadores resultam em diferentes efeitos para os beneficiários, os alunos e suas famílias. Em pesquisa sobre a política educacional de correção de fluxo no Rio de Janeiro, Oliveira e Paes de Carvalho (2019), por exemplo, afirmam que as lógicas de ação dos implementadores investigados - professores e diretores - vão além das prescrições formais, incluindo processos de julgamento, classificação e seleção sobre os usuários da política - os alunos. 
Considerando o período atípico que estamos atravessando, os encaminhamentos para minimizar os efeitos da suspensão das atividades letivas na educação básica se materializam em políticas locais, como discutido na introdução deste texto. A definição do que poderíamos chamar de "políticas educacionais emergenciais" acontece em um novo contexto, onde o espaço escolar foi virtualmente ampliado, assim como as relações entre educadores e alunos e a própria relação ensino-aprendizagem, mediadas pelas tecnologias da informação e do conhecimento, largamente difundidas e utilizadas durante a pandemia.

Assumindo que as Secretarias de Educação não estavam preparadas para tal situação, consideramos que a formulação dessas ações emergenciais se deu em um período bastante reduzido, aumentando os níveis de incerteza e ambiguidade dos programas desenhados. Como não houve tempo para se construir estratégias que vinculassem e articulassem os profissionais da educação que atuam na linha de frente - os burocratas de rua, entendemos que a adesão desses atores é bastante heterogênea. Ao implementar um programa de educação ancorado no uso das tecnologias, as Secretarias potencializam a discricionariedade desses atores, além de induzir níveis distintos de comprometimento e motivação, muito dependentes da ação individual desses atores, profissionais que, também, estão expostos às dificuldades que a pandemia impõe.

\section{Minas Gerais e a Secretaria Estadual de Educação: aspectos socioeconômicos, educacionais e ações de enfrentamento da pandemia}

Com 21 milhões de habitantes, Minas Gerais é o segundo estado mais populoso do país e é o que tem o maior número de cidades, totalizando 853 municípios. Segundo Queiroz (2001), o estado é uma das regiões mais heterogêneas do país. Coexistem regiões dinâmicas, modernas e com elevados indicadores socioeconômicos e localidades empobrecidas e pouco desenvolvidas.

O nível de desenvolvimento dessas regiões é medido pelo Índice de Desenvolvimento Humano Municipal (IDH-M). Segundo dados da Fundação João Pinheiro (FJP), os maiores valores para esse indicador estão nas regiões sudoeste, sul, sudeste e na Região Metropolitana de Belo Horizonte (RMBH), consideradas as mais desenvolvidas. Por outro lado, as mesorregiões localizadas nas regiões norte, noroeste e nordeste são as menos desenvolvidas e, portanto, as mais desiguais.

Ainda que não respondam por um número expressivo de habitantes, metade da população dessas regiões vive em situação de pobreza e extrema pobreza. Segundo dados da 
FJP, a proporção de pessoas que vive em domicílios com renda igual a zero é relativamente alta quando comparada com as demais regiões. Por outro lado, apesar de a Região Metropolitana de Belo Horizonte (capital do estado) ser uma das mais desenvolvidas do estado, quase $25 \%$ da população pobre do estado localiza-se nessa área.

Com relação à utilização da Internet no estado, segundo a Pesquisa Nacional por Amostra de Domicílio Contínua (Pnad C) do IBGE (2018), do total de habitantes mineiros, $74,8 \%$ utilizaram Internet e $25,2 \%$ não a utilizaram. Conforme dados do IBGE, em 79,3\% dos domicílios particulares mineiros há utilização de Internet. Em 99,4\% desses, a utilização é via telefone móvel celular; $50,2 \%$ por meio de microcomputador e $14,7 \%$ usam tablet. Sobre o acesso, em 58\% dos domicílios a conexão se dá via banda larga fixa e móvel; em 57,9\% somente via banda larga. 97\% dos domicílios mineiros tem aparelho de televisão.

No campo educacional, os dados do Censo Escolar (2019) informam que Minas Gerais tem mais de 4,1 milhões de alunos matriculados nas redes municipais, estadual, federal e privada. Segundo o Censo, 85\% delas estão nas áreas urbanas. Desses, pouco mais de 1,8 milhões são alunos da rede estadual ${ }^{5}$, sob a responsabilidade da SEE, que gerencia 3.603 escolas em todo o estado. Desse total, 3.288 unidades estão em zonas urbanas e 324 localizam-se em zona rurais, abrigando $85,3 \%$ e $14,7 \%$ das matrículas, respectivamente. Do total de alunos matriculados na rede estadual mineira, 50,2\% são do sexo feminino e 49,8\% masculino. Quanto à raça/cor, 30,7\% se declaram brancos, $49,1 \%$ pardos, $6,2 \%$ pretos, $0,3 \%$ indígenas, 0,2\% amarelos e 13,5\% não declararam sua cor.

Além das escolas urbanas e rurais, a SEE também é responsável por estabelecimentos educacionais que oferecem Educação Especial Exclusiva (0,72\%), abrigando aproximadamente 2.494 estudantes. Com relação à Educação do Campo, Educação Indígena e Educação Quilombola, o estado conta com 17 estabelecimentos, empregando 519 professores, dentre os quais 62 possuem formação em Magistério Específico Indígena. Quanto à Educação do Campo, são atendidas 21 Escolas Família Agrícola (EFA), que atendem 2000 estudantes em mais de 1200 comunidades, com o apoio do Governo do Estado.

Segundo publicação da SEE (MINAS GERAIS, 2017), a rede estadual conta com 15.561 diretores escolares e emprega 96.783 professores. Desses, $35,5 \%$ são efetivos e $67,7 \%$ são temporários. Do total, 23,5\% são do sexo masculino e $76,5 \%$ do sexo feminino. Quanto à faixa etária, $11,5 \%$ têm até 29 anos de idade, a maioria $(66,6 \%)$ situa-se na faixa etária entre

5531 alunos estão matriculados na Educação Infantil (Pré-Escola); 1.099 .619 no Ensino Fundamental (Séries Iniciais e Séries Finais) e 737.613 no Ensino Médio. 
30 e 49 anos e 21,9\% têm 50 anos ou mais. Quanto à raça/cor, 18,1\% se situam na categoria de não declarados; $40,1 \%$ se declaram como brancos; $41,1 \%$ negros e $0,5 \%$ indígenas.

Em relação à remuneração dos profissionais da educação, o salário de Professor da Educação Básica (PEB) varia entre R\$1.455,30 e R 2.135,64, para jornadas de trabalho de 24 horas. A remuneração média do Diretor de Escola é R\$ 6.741,48. O Especialista em Educação Básica (EEB), responsável pelo trabalho de orientação, implementação e avaliação do processo de ensino e aprendizagem nas escolas, tem remuneração média de R\$ 3.481,20.

Com relação ao Nível Socioeconômico ${ }^{6}$, as escolas estaduais mineiras estão concentradas nos grupos 3 e 4 (56,5\% e 27,3\%, respectivamente). Com relação ao Ideb, a figura 1 traz a distribuição do indicador para cada município mineiro, evidenciando o contraste entre as regiões norte (6,0 Anos Iniciais; 4,1 Anos Finais), nordeste e sul (6,7 Anos Iniciais; 4,9 Anos Finais) do estado. Enquanto as duas primeiras apresentam os piores indicadores educacionais (coincidindo com os dados indicados anteriormente), a região sul é a que tem melhor desempenho escolar, associado a elevado nível socioeconômico.

Figura 1 - Ideb dos municípios de Minas Gerais

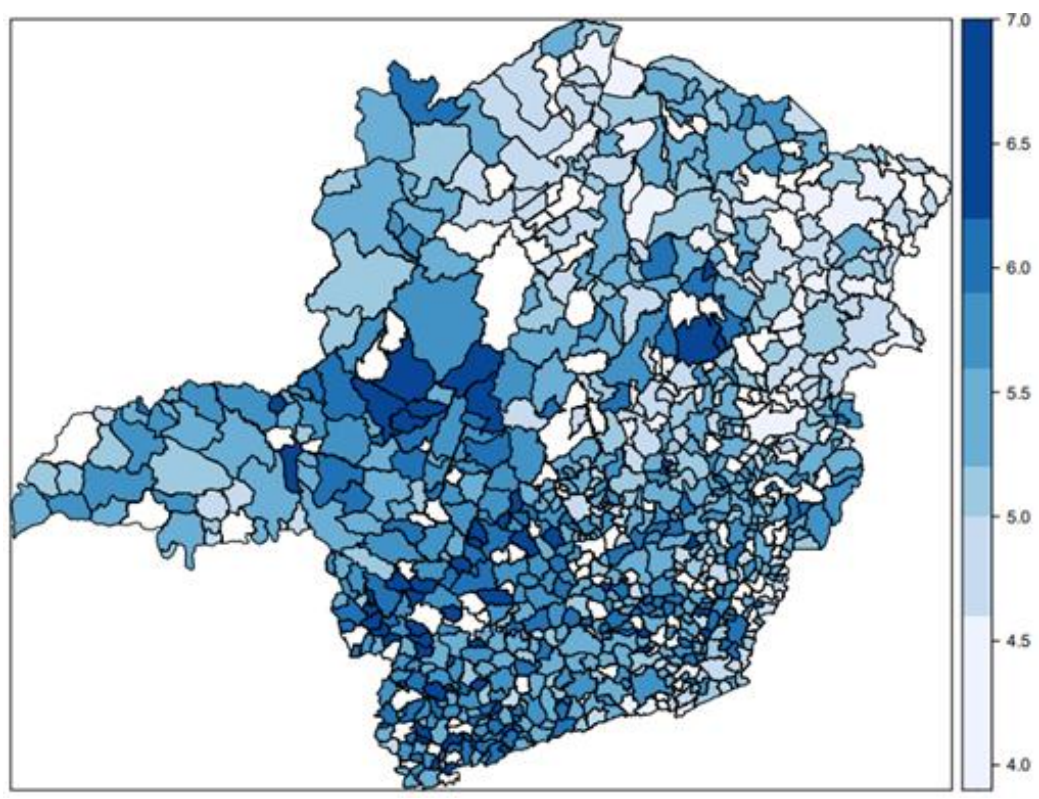

Fonte: Elaborado pelos autores

Segundo Pereira e Silva (2020), a relação entre a SEE e os professores é complexa. Além das históricas disputas entre os trabalhadores e o Estado por maior remuneração e

${ }^{6}$ O Indicador de Nível Socioeconômico (Inse) foi elaborado com base nos microdados dos questionários contextuais do Sistema de Avaliação da Educação Básica (Saeb) e do Exame Nacional do Ensino Médio (Enem). O Inse é um valor numérico que varia de 1 a 6 , em que o nível 1 congrega escolas de Inse médio mais baixo e o nível 6, escolas pertencentes ao grupo com Inse mais alto (ALVES, SOARES e XAVIER, 2014). 
melhores condições de trabalho, Minas Gerais ainda não cumpre com o piso nacional do magistério. Segundo pesquisa realizada pelo Grupo de Estudos Sobre Política Educacional e Trabalho Docente (GESTRADO, 2017), a remuneração média dos professores é uma das menores do país, agravada pelo choque de gestão imposto pelos governos de Aécio Neves (2003-2006/2007-2010) e Antônio Anastasia (2010-2014), ambos do Partido da Social Democracia Brasileira (PSDB). O número de professores contratados também é elevado, o que, invariavelmente, faz com que a pressão por concursos públicos seja constante. Já no governo de Fernando Pimentel, do Partido dos Trabalhadores (2015-2018), a greve realizada pelos profissionais da educação em 2018, motivada pela revogação da chamada Lei $100^{7}$, agravou a relação entre os professores e o executivo estadual.

A eleição de Romeu Zema, em 2018, inaugura um novo ciclo no estado. Empresário filiado ao Partido Novo, Zema venceu as eleições com a promessa de modernizar e fortalecer a gestão pública. Com a crise orçamentária agravada pelas gestões anteriores, Zema tem implementado uma agenda notadamente liberal, marcada por cortes de gastos e investimentos públicos, restrições nas contratações de pessoal e privatizações.

Os crimes ambientais em Mariana pioraram a situação fiscal do estado. A queda na arrecadação proveniente da mineração, associada à retração econômica do país, obrigou o governo Pimentel a escalonar o pagamento dos servidores estaduais, incluindo os profissionais da educação. Os professores passaram a receber seus vencimentos em até três parcelas, pagas com relativo atraso e sem cronograma fixo. Mantida pelo governo Zema, tal medida aprofundou o desgaste entre o executivo e seus servidores, que tem priorizado o pagamento dos profissionais da segurança pública em detrimento de outras carreiras.

Ainda segundo Pereira e Silva (2020), a nomeação de Julia Sant'anna para o cargo de Secretária de Estado da Educação nessa gestão piorou ainda mais a relação com os docentes. Carioca, servidora concursada do estado do Rio de Janeiro na carreira de especialista em Políticas Públicas e Gestão Governamental, a Secretária não conhece, em profundidade, a realidade do estado e as especificidades da educação mineira.

É esse o contexto educacional do estado quando a Pandemia da COVID-19 assola o país e o mundo, no início de 2020. Diante do quadro caótico que se anunciava no país em função das posições contraditórias, erráticas e desarticuladas adotadas pelo governo federal,

${ }^{7}$ Em novembro de 2007, o governo publicou a Lei Complementar $n^{\circ} 100$, conferindo aos servidores públicos da educação que estavam contratados temporariamente o status de servidor efetivo. O estado estendeu os direitos exclusivos dos servidores detentores de cargo público efetivo aos servidores efetivados pela LC 100/07. Em 2010, o Tribunal de Justiça do estado declarou a inconstitucionalidade da Lei. Em 26 de março de 2014, o Supremo Tribunal Federal (STF) a declarou inconstitucional, atingindo 96 mil trabalhadores da educação.

RIAEE - Revista Ibero-Americana de Estudos em Educação, Araraquara, v. 16, n. 1, p. 84-106, jan./mar. 2021. e-ISSN: 1982-5587 
os estados e municípios passaram a agir em bloco. No dia 12 de março o governo mineiro declarou situação de emergência em razão do surto provocado pelo Novo Coronavírus.

Em 15 de março, novo decreto do Executivo Estadual determinou o início da quarentena e inaugurou o início do trabalho remoto dos servidores, além do isolamento daqueles que estiveram em áreas com transmissão comunitária do vírus. Na mesma data, o Comitê Extraordinário da Covid-19 determinou a suspensão das aulas em todas as escolas da rede estadual em Minas entre os dias 18 e 22 do referido mês. No dia 22 de março, a suspensão das aulas em todas as unidades da Rede Pública Estadual passou a ser indefinida. Tais medidas aplicaram-se também às instituições privadas de ensino e às redes municipais.

Em 09 de abril, o Comitê Extraordinário da Covid-19 determinou a volta às atividades dos diretores, vice-diretores, além de assistentes técnicos de educação, analistas e auxiliares de educação básica, em regime de teletrabalho. No dia 18 de abril foi publicada a resolução ${ }^{\circ}$ 4.310, que institui o Regime Especial de Teletrabalho nas Escolas Estaduais da Rede Pública de Educação e o Regime Especial de Atividades Não Presenciais (REANP), apresentado por meio de um portal, que pode ser acessado publicamente ${ }^{8}$. As medidas foram adotadas para reestabelecer o calendário escolar, interrompido na modalidade presencial.

\section{Educação remota em Minas Gerais: o Regime Especial de Atividades Não Presenciais}

De acordo com a SEE, o modelo de estudo remoto adotado no estado foi desenvolvido em sintonia e diálogo com professores, equipe pedagógica e instituições ligadas à educação, articulando diversos atores em uma perspectiva multinível: secretarias estaduais, superintendências regionais de ensino, Prodemge ${ }^{9}$, emissoras de TVs públicas, Assembleia Legislativa, sindicatos, operadoras de telefonia, provedores de Internet, empresas de plataformas e mídias digitais, famílias, profissionais da educação e alunos. A expectativa era a de que o maior número possível de alunos fosse atingido e, assim, tivessem seu direito à educação garantido. Nesse contexto, o REANP organiza-se em três eixos: (i) o Plano de Estudos Tutorados (PET), (ii) o Programa Se Liga na Educação e (iii) o aplicativo Conexão Escola.

Ao virtualizar a sala de aula, os espaços e os tempos formativos, o objetivo da SEE é oferecer estratégias diversas para que todos os alunos tenham acesso aos recursos e para que

${ }^{8}$ O portal do REANP. Disponível em: https://estudeemcasa.educacao.mg.gov.br/inicio. Acesso em: $10 \mathrm{dez}$. 2020.

${ }^{9}$ A Prodemge é uma empresa de tecnologia da informação do governo de Minas Gerais, responsável por auxiliar órgãos e instituições públicas no estado. 
possam chegar ao maior número possível de alunos. Cada aluno, porém, utilizará aquela que lhe for mais conveniente e acessível. Quanto aos professores, é esperado que estabeleçam a melhor forma de comunicação com seus alunos, que poderá ser via e-mail, telefone ou aplicativo de mensagens, por exemplo. A partir das contribuições de Lévy (2011) e Oliveira e Daroit (2020), a escola torna-se, portanto, um território virtual, liquidamente diluído nos espaços, nas dinâmicas dos domicílios e das pessoas que neles habitam.

O Plano de Estudo Tutorado (PET)

Os Planos de Estudos Tutorados (PETs) foram organizados de acordo com o Currículo Referência de Minas Gerais (CRMG), com o Plano de Curso da unidade de ensino e com a carga horária prevista nas matrizes curriculares dos diferentes níveis e modalidades de ensino. Os PETs são um instrumento de aprendizagem que permite ao estudante resolver questões e atividades escolares programadas, de forma autoinstrucional e não presencial.

Organizado na forma de apostilas com conteúdo e atividades referentes a cada ano/série escolar, respeitando a carga horária mensal da disciplina para cada estudante, o material abrange as seguintes disciplinas do Ensino Médio ${ }^{10}$ : Língua Portuguesa, Matemática, Biologia, Química, Física, História, Geografia, Filosofia, Sociologia, Língua Inglesa, Estudos Orientados e Projeto de Vida. Para atender ao Ensino Médio, estão disponíveis para download 12 volumes para o $1^{\circ}$ ano, 8 para o $2^{\circ}$ ano e 8 para o $3^{\circ}$ ano. Segundo a SEE, os alunos devem entregar as atividades do PET para correção no retorno das aulas presenciais. Os professores das disciplinas, por sua vez, deverão analisar o material, orientando os estudantes sobre os conteúdos, propondo atividades complementares e apoiando a resolução dos exercícios ${ }^{11}$. Para os alunos da educação especial, os PETs deverão ser adaptados pelas escolas de acordo com o Plano de Desenvolvimento Individual (PDI) do estudante.

Os PETs estão disponíveis no site da SEE, no portal que congrega todas as ações e informações relativas ao REANP e no aplicativo Conexão Escola. Além disso, os arquivos em PDF poderão também ser enviados para os e-mails dos pais e/ou responsáveis, dos alunos e dos professores cadastrados na escola e por outras ferramentas digitais. Para os estudantes que não possuem acesso à Internet, a escola deverá assegurar que o material impresso seja disponibilizado ao estudante. Com o apoio das 47 Superintendências Regionais de Ensino, caberá às escolas identificar como o material chegará a todos os estudantes.

Programa Se Liga na Educação

${ }^{10}$ Para fins deste estudo, foram considerados apenas os materiais referentes as séries do Ensino Médio.

${ }^{11}$ Diversas foram as matérias jornalísticas que veicularam informações sobre a incorporação de trechos copiados sem a devida citação das fontes e com imprecisões ou inconsistências de conteúdo.

RIAEE - Revista Ibero-Americana de Estudos em Educação, Araraquara, v. 16, n. 1, p. 84-106, jan./mar. 2021. e-ISSN: 1982-5587 
O Programa Se Liga na Educação é uma das três ações do REANP. Em formato de teleaula, as aulas são transmitidas pela Rede Minas e pela TV Assembleia e são ministradas por professores da SEE. As gravações privilegiam conteúdos nos quais os alunos apresentam, historicamente, maior grau de dificuldade e são planejadas para os alunos do $4^{\circ}$ ano do Ensino Fundamental ao $3^{\circ}$ ano do Ensino Médio. As teleaulas são exibidas na programação diária da Rede Minas e na TV Assembleia, de segunda a sexta-feira ${ }^{12}$. Entre 7h30min e $11 \mathrm{~h} 15 \mathrm{~min}$ são exibidas teleaulas gravadas. Cada 20 minutos é dedicado a um ano de escolaridade. $\mathrm{O}$ momento de conteúdo ao vivo com interação é das $11 \mathrm{~h} 15 \mathrm{~min}$ às $12 \mathrm{~h} 30 \mathrm{~min}$.

As teleaulas estão disponíveis, também, no canal da Educação no Youtube e na página da Rede Minas, o que permite o acesso ao conteúdo e sua visualização por meio on-line e assíncrono. As aulas também podem ser acessadas por meio do aplicativo Conexão Escola.

Aplicativo Conexão Escola

O Aplicativo Conexão Escola é uma plataforma de acesso gratuito para o aluno e professor da rede pública estadual de ensino. A plataforma permite ao aluno acesso aos canais de transmissão das teleaulas (Programa Se Liga na Educação, exibido na Rede Minas ${ }^{13}$ ) e aos PETs para realização de download, sem a necessidade de utilizar seu pacote de dados, além de poder acessar salas de chat para interagir com seus colegas e professores. $\mathrm{O}$ aplicativo pode ser acessado exclusivamente por dispositivos móveis com sistema operacional Android.

\section{REANP: o que dizem os alunos, professores e responsáveis?}

A análise dos comentários postados sobre o aplicativo e sobre as teleaulas (no Youtube) se deu a partir de sete dimensões: (1) o acesso ao programa; (2) a receptividade ao REANP; (3) percepções sobre o aplicativo e suas funcionalidades (4) questões associadas à tecnologia; (5) conteúdo; (6) adesão à educação remota e (7) conexão entre os eixos do Programa.

\section{O acesso ao programa}

As ferramentas digitais (aplicativo e programa de TV), bem como o PET (que pode ser lido na tela no formato PDF e/ou impresso) compõem ações que devem ser compreendidas de

12 O programa é transmitido no canal aberto da Rede Minas e da TV Assembleia (canais públicos no estado), e por meio das antenas parabólicas com sinal via satélite. Assinantes de canis a cabo têm acesso à programação.

${ }^{13}$ As teleaulas são disponibilizadas no aplicativo em até 12 horas depois de exibidas no Programa Se Liga na Educação. 
maneira integrada e transversal: são canais de formação complementares e que possuem desenhos diferentes. Nesse sentido, exigem o domínio de estratégias distintas para sua utilização. Para tal, os usuários (alunos e professores) precisam saber ler na tela; saber como assistir teleaulas ao vivo e online. É necessário, ainda, que eles se apropriem das possibilidades de articulação entre essas ferramentas, potencializando o seu uso.

O número de usuários dessas ferramentas, embora seja bastante expressivo, levanta questionamentos sobre a capacidade de abranger todos os estudantes da rede estadual. As famílias e os alunos têm condições de acessar? Que dificuldades há?

Até o dia 06 de julho de 2020, o aplicativo foi baixado por mais de 1 milhão de usuários e as teleaulas foram visualizadas mais de 7 milhões de vezes. Os números, embora bastante expressivos, não impedem que questionemos os limites de abrangência do REANP proposto pela SEE. O aplicativo, por exemplo, só pode ser baixado por aparelhos cujo sistema operacional é o Android, o que exclui os aqueles que funcionam pelo sistema IOS. A obrigatoriedade de uso de aparelhos que operam pelo sistema fica, então, subentendida.

$\mathrm{O}$ acesso à Internet também é pressuposto básico para que estudantes e professores possam utilizar as ferramentas oferecidas a eles. Para assistir os programas exibidos pela Rede Minas e pela TV Assembleia, é imprescindível o acesso à energia elétrica, aparelho de TV e, certamente, residir em áreas que recebam o sinal desses canais. Ainda que os dois canais sejam públicos (a Rede Minas é mantida pelo governo do estado), o sinal da Rede Minas chega a apenas 183 dos 853 municípios. Com o aporte da TV Assembleia, mais 79 localidades foram incluídas. De todo modo, pouco mais de 270 municípios estão tendo cobertura, o que equivale a $32 \%$ do total. De acordo com a SEE, apenas 1 milhão, dos 1,8 milhões de alunos da rede estadual terão acesso às aulas remotas por meio da TV.

Aproximadamente 700 mil alunos (39\%) estão sem acesso às teleaulas pela TV e, assim, sem possibilidade de terem suas dúvidas sanadas em tempo real. Não podemos tratar como coincidentes os fatos de termos 1 milhão de alunos com acesso ao programa de TV e de a mesma quantidade ter baixado o aplicativo. Embora não tenhamos tido acesso ao número de downloads do PET, estimamos que os alunos que tiveram acesso ao site "Estude em Casa" e/ou ao aplicativo tiveram melhores condições de acesso às ferramentas de estudo propostas pela SEE. Os outros demais estudantes tiveram de se valer de estratégias outras para acessarem os materiais e participarem minimamente do regime de estudo proposto pela SEE. A receptividade ao REANP

Os estudantes e professores que acessaram o aplicativo (pelo Google Play) e as teleaulas (pelo YouTube) poderiam manifestar sua satisfação ou não com essas ferramentas 
por meio das avaliações possibilitadas pelas suas respectivas plataformas de distribuição. No caso das teleaulas, era possível dar like e deslike (gostei não gostei) nos vídeos postados. A tabela 1 traz as informações compiladas a partir dos dados do canal.

Tabela 1 - Vídeos do "Se Liga na Educação" disponíveis no canal do Youtube

\begin{tabular}{|c|c|c|c|c|c|c|c|c|}
\hline & $\begin{array}{l}\text { Período/ } \\
\text { Atde. }\end{array}$ & maio & junho & $\begin{array}{c}\text { Média de } \\
\text { duração/vídeo }\end{array}$ & Visualizações & Comentários & Likes & $\begin{array}{l}\text { [Des] } \\
\text { likes } \\
\end{array}$ \\
\hline \multirow{6}{*}{ 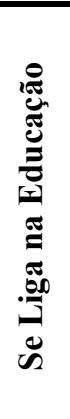 } & Matemática & 02 & 02 & 5 horas & 1.637 .809 & 3.036 & $\begin{array}{l}62,1 \\
\text { mil }\end{array}$ & 8.698 \\
\hline & $\begin{array}{l}\text { Ciências da } \\
\text { Natureza }\end{array}$ & 02 & 03 & 5 horas & 1.529 .820 & 2.749 & $\begin{array}{c}65,2 \\
\text { mil }\end{array}$ & 7.364 \\
\hline & Linguagens & 01 & 04 & 5 horas & 1.731 .786 & 3.321 & $65 \mathrm{mil}$ & 9.500 \\
\hline & $\begin{array}{l}\text { Ciências } \\
\text { Humanas }\end{array}$ & 01 & 04 & 5 horas & 2.037 .341 & 3.201 & $\begin{array}{c}57,7 \\
\text { mil }\end{array}$ & 10.402 \\
\hline & $\begin{array}{l}\text { Conteúdo } \\
\text { do Enem }\end{array}$ & 02 & 02 & 5 horas & 462.508 & 315 & 16.810 & 1.631 \\
\hline & Total & 08 & 15 & 25 horas & 7.363.264 & 12.622 & 266.810 & 37.595 \\
\hline
\end{tabular}

Fonte: Elaborada pelos autores

Nesse caso, likes e deslikes podem ser usados como parâmetro para avaliar se o conteúdo apresentado correspondeu à expectativa do público ao qual se destinou. $\mathrm{O}$ aplicativo Conexão Escola poderia ser avaliado pelos usuários do Google Play por meio da atribuição de notas por categorias, sendo 5 a maior nota e 1 a menor. Os usuários atribuíram a nota média de 2.8 ao aplicativo. Eles podem avaliar apenas uma vez, mas, se desejarem, podem aumentar ou diminuir o número de estrelas que dão ao aplicativo.

Assim, foi possível realizar uma análise exploratória em um universo de 5.305 comentários do Google Play e 12.622 comentários sobre as teleaulas no Youtube. Os dados informam que há, no caso do aplicativo e Youtube, visões aparentemente contraditórias. Temos, por um lado uma atribuição expressiva de 5 estrelas para o aplicativo; do outro, uma elevada concentração de avaliações muito ruins. Algo análogo ocorreu com os likes e deslikes nos vídeos das teleaulas. Encontramos uma quantidade expressiva de likes em detrimento dos deslikes. Todavia, os comentários relacionados aos vídeos demonstravam insatisfação com as ferramentas, além de, obviamente, fazerem referência às teleaulas.

\section{Percepções sobre o aplicativo e suas funcionalidades}

O aplicativo foi projetado em regime de urgência e talvez por isso não tenha sido possível apresentar uma versão mais elaborada. O número de avaliações negativas da 
ferramenta é expressivo. Há relatos que apontam dificuldades de acesso e incompatibilidade com aparelhos celulares: "as aulas demoram a cair; e o pessoal que tem iphone?".

Também há muitos comentários sobre as dificuldades em acessar o chat disponível no aplicativo. As maiores reclamações relativas ao chat revelam: instabilidade; mensagens que “desaparecem"; impossibilidade de gravar áudios, enviar documentos ou links que exibam seu conteúdo: "o chat dá erro direto" (aluno); "tenho que ficar procurando qual é meu (aluno)"; "...não tem notificação quando o aluno chama no chat (professor)".

Os comentários elogiosos existem, mas em menor proporção. Eles revelam que, uma vez aprimorado, o aplicativo é uma ferramenta que poderia permanecer sendo usada, mesmo após a pandemia: "eu acho super legal, dá pra entender as matérias (aluno)"; "muito bom!" "(...) minha filha consegue a direção e faz muitas atividades (responsável)"; "(...) a qualidade do vídeo é boa, recomendo (aluna)".

Tecnologia

No caso do aplicativo, os usuários relatam que as suas funcionalidades são incompatíveis com celulares antigos. Os dados socioeconômicos dos alunos (e suas famílias) matriculados na rede pública estadual revelam pertencimento aos extratos inferiores. Assim, não são raros os comentários que indicam a dificuldade em possuir ou vir a adquirir um celular sofisticado o suficiente para suportar a tecnologia demandada pelo aplicativo: "vocês querem que eu compre um celular com dinheiro emergencial? (aluno)"; "(..) esse dinheiro gasto para o sustento da família... (aluno)".

Em relação à qualidade técnica das teleaulas disponíveis no canal da Rede Minas no YouTube, os comentários postados pelos alunos e seus responsáveis tratam da qualidade do áudio ("o áudio está muito baixo, Rede Minas") e, também, da informação sobre início e fim de cada aula, a chamada "minutagem". Uma vez que os vídeos possuem até cinco horas de duração, os usuários têm extrema dificuldade em localizar as aulas que são destinadas ao ano que estão cursando: "Sem condições! Gente façam uma Play List com os anos respectivos, para que nós, pais, possamos acessar as aulas... pois nessa bagunça é impossível dar andamento...".

Tanto em relação ao aplicativo quanto ao acesso ao Youtube, os usuários afirmam que a qualidade do sinal da Internet dificultava os seus estudos. Houve relatos que revelam a desigualdade na qualidade do sinal de Internet em Minas Gerais: "o carregamento é muito demorado"; "...tento entrar no app o dia inteiro, mas não consigo". Como a educação remota é dependente do acesso às tecnologias, assume-se que a assimetria no acesso do sinal da 
Internet pode contribuir no aumento da desigualdade educacional no estado e, por extensão, no país.

Os comentários relacionados à qualidade técnica do aplicativo e teleaulas remetem aos Objetos de Aprendizagem, que podem ser impressos, audiovisuais e voltados para o uso na Internet. A literatura classifica esses objetos como qualquer recurso que possa ser reutilizado para apoiar o aprendizado. O seu uso prevê ou deveria prever a articulação entre diversas instituições para que objetos produzidos fossem compartilhados (MARTIN; RITZHAUPT, 2020). Essa possibilidade diminuiria os custos para as instituições de ensino e os seus patrocinadores. Como no Brasil as ações associadas à pandemia têm sido marcadas pela baixa e descoordenada articulação federativa, os custos econômicos e sociais podem ser maiores, comprometendo os resultados esperados. Kampen (2020) sugerem que, para alunos que não têm dispositivos eletrônicos ou acesso à Internet, sejam sugeridas tarefas para serem realizadas com papel e lápis. Além disso, é preciso criar alternativas para a entrega dessas tarefas, ainda que seja na volta às aulas.

\section{Conteúdo}

Nessa dimensão, analisamos os comentários que se referiam ao conteúdo dos recursos disponibilizados no aplicativo - videoaulas e as apostilas do PET, além das teleaulas que estão no Youtube. Diferentemente do canal no Youtube gerenciado pela TV Minas, no aplicativo, os vídeos estão editados, por área, tema/conteúdo e série, conforme disposto na Tabela 2. Nesse caso, a navegabilidade é mais amigável, facilitando o acesso dos usuários. As teleaulas, por sua vez, têm duração média de cinco horas, sem minutagem.

Tabela 2 - Vídeos disponíveis no aplicativo "Conexão Escola Web"

\begin{tabular}{|c|c|c|c|c|c|c|}
\hline & Ano Escolar & $\mathbf{1}^{\mathrm{o}}$ & $2^{\circ}$ & $3^{\circ}$ & $\begin{array}{c}\text { Média de } \\
\text { duração/vídeo }\end{array}$ & $\begin{array}{c}\text { Avaliações } \\
\text { sobre o } \\
\text { Aplicativo }\end{array}$ \\
\hline \multirow{6}{*}{ 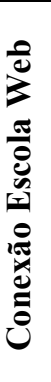 } & Matemática & 06 & 04 & 10 & 20 minutos & \multirow{6}{*}{5.686} \\
\hline & $\begin{array}{c}\text { Ciências da Natureza } \\
\text { [Química/Física/Biologia] }\end{array}$ & 05 & 05 & 10 & 20 minutos & \\
\hline & $\begin{array}{c}\text { Linguagens } \\
\text { [Língua Portuguesa/Língua Inglesa] }\end{array}$ & 05 & 05 & 10 & 20 minutos & \\
\hline & $\begin{array}{c}\text { Ciências Humanas } \\
{[\text { História/Geografia/Filosofia/Sociologia }]}\end{array}$ & 05 & 05 & 10 & 20 minutos & \\
\hline & Conteúdo do Enem & - & - & 50 & 20 minutos & \\
\hline & Tira Dúvidas & & 18 & & 50 minutos & \\
\hline
\end{tabular}

Fonte: Elaborada pelos autores 
Os comentários indicam que os alunos se valem de estratégias distintas para utilizarem as videoaulas. Os comentários são bastante heterogêneos, o que revela a subjetividade aí diluída. Para um grupo de usuários (alunos, professores e responsáveis), as aulas são curtas, superficiais, difíceis de serem compreendidas ou são descontextualizadas, quando comparadas com o PET e com as diretrizes curriculares adotadas pela SEE. Outros comentários apontam a ausência de componentes curriculares que ainda não foram contemplados. Muitos alunos reclamam dos professores, dizendo que as aulas são confusas e que não conseguem acompanhar: "é muito pouco tempo de aula" (responsável); "os vídeos são desorganizados e não possuem datas e títulos" (aluno); "efetivamente fora das normas da BNCC" (professor).

Como estão separados por assunto, os vídeos têm, em geral, 20 minutos de duração. Em tempos virtuais, onde a dimensão do tempo é relativa e a interação com a tela faz com que a relação seja mais efêmera, instantânea e fragmentada, uma aula com duração de 20 minutos tanto pode ser longa quanto curta, dependendo de quem a assiste, de suas motivações, habilidades, competências e estoques de capital cultural, social, econômico e simbólico.

Os comentários em relação ao conteúdo das teleaulas que estão no YouTube revelam que essas aulas não se comunicam com o que é oferecido no PET. É possível perceber, ainda, o desencontro entre o que os alunos sabem e o que os professores supostamente acreditam que eles saibam: "por favor, exibam as aulas em sincronicidade com os PETs. Sem uma sequência pedagógica de conteúdo fica difícil criar hábito no aluno e ajudar ao professor ..." (professor); "o professor de inglês trata dos assuntos como se nós entendêssemos tudo que ele fala na outra língua" (aluno); "Será só eu que não estou entendendo nada de nada? Haaaaaaaaaa" (aluno); "como vou fazer as atividades sendo que o PET não condiz com o que os professores passam?" (aluno).

Se, por um lado, há os que manifestam descontentamento, há os que estão satisfeitos, que os conteúdos têm contribuído para a formação; que as aulas são bem elaboradas e que os professores têm sido competentes: "dá para aprender bem fazendo além das aulas dadas" (aluno); "(...) o app é muito bom (...) os vídeos são muito bons. Aprendo bastante" (aluno).

As questões técnicas que emergem dos comentários dos alunos, bem como os relacionados ao conteúdo, favorecem a reflexão sobre como implementar a educação remota, o que priorizar e onde estão as fraturas. Eles podem balizar a avaliação do que está sendo oferecido e proporcionar mudanças e intervenções que se fazem urgentes. 


\section{Adesão/Resistência}

Assumimos que a adesão às ferramentas do Programa está diretamente associada à adesão ao Programa em si. Novamente, os comentários revelam que as percepções são diferentes. Há um número significativo de postagens contrárias ao Programa, com relatos de usuários que informam que não estão aprendendo e que os vídeos não contribuem para a formação: "tudo está muito confuso para todos, desde o aplicativo, até o PDF que nos disponibilizam (aluno); ninguém está entendendo nada dessas aulas online" (aluno); "(...) do que adianta ter aula, se não aprendemos nada?" (aluno).

Ainda que outra metodologia de análise fosse necessária, os dados sugerem que há estreita correlação entre a resistência e o fato de as aulas serem remotas e virtuais. A baixa adesão está relacionada com a dificuldade que os alunos têm em se adaptar às estratégias de formação que são diferentes das adotadas na educação presencial, o paradigma que, para a totalidade dos alunos e a imensa maioria dos responsáveis, era a única referência existente. Além dessas questões, é fundamental considerar que as novas estratégias adotadas pela SEE agravam e aprofundam as dificuldades dos alunos em aprender.

Todavia, há comentários que indicam que os usuários compreendem a conjuntura e o contexto em que estão, além de reconhecer o esforço que os professores que estão ministrando as aulas têm feito: "não vou dizer que está sendo fácil, mas deixo aqui meus cumprimentos aos professores que se esforçam tanto" (aluno); "Mas todos estão se reinventando e se cada um tentasse dar o seu melhor ao invés de criticar e julgar, garanto que os resultados seriam bem melhores" (responsável).

Nesses casos, os comentários sugerem que há um processo de mudança em curso, uma vez que os professores (e a SEE) estão se reinventando. Ainda que novas pesquisas e metodologias sejam necessárias para se avançar nessa discussão, os dados sugerem que tais experiências podem trazer contribuições importantes para se rever as estratégias pedagógicas adotadas antes da pandemia, modificando o paradigma da formação após seu término.

\section{Conexão entre os eixos}

Nesta categoria analisamos como os usuários percebem as conexões entre o aplicativo e os demais canais e eixos de formação adotados pela SEE - Se liga na Educação e o PET. Como se trata de um programa multinível, que articula diversos atores institucionais e sujeitos, e virtualiza o espaço e os tempos da escola, verificar se e como os usuários percebem a transversalidade entre os eixos contribui para melhor compreender o desenho e os efeitos 
pretendidos pelo programa, além de fornecer subsídios para a melhoria da gestão das ações empreendidas pela SEE e demais atores institucionais envolvidos.

Como a referência para os alunos é a educação presencial (para as famílias e os professores também), e a pandemia não deu a eles condições (nem tempo) para adaptarem-se e transitar para novas modalidades e abordagens, as reações dos alunos refletem insegurança, medo, solidão e despreparo. Três trechos reforçam esse argumento: "Socorro! Quero minha sala de aula de volta!" (aluno); "Não vamos aprender em 20 minutos o conteúdo de uma aula inteira! Estou perdido" (aluno); "quase todos com quem conversei me dizem que não estão entendendo nada e não sabem como isso está funcionando. Estamos abandonados" (aluno).

Os comentários apontam para a dificuldade que os alunos têm demonstrado em articular os eixos de formação assíncronos, os recursos e as mídias disponibilizadas pela Secretaria. Como, agora, são os alunos (e seus responsáveis) os principais responsáveis pelo planejamento do percurso formativo com o apoio da SEE e dos professores, a gestão desse processo tem se mostrado complexa e confusa. Os excertos destacados tratam dessas questões: "e aquele pdf obviamente traz as atividades correspondentes a cada matéria, mas como fazer se nem tem a aula para compreender?" (aluna); "Aparecem no meu app PET's de outras modalidades de ensino (p mim poderia aparecer só o PET do primeiro ano do ensino médio regular diurno, mas aparecem os de ensino integral, etc.). Tenho que ficar procurando qual é o meu e perco tempo. É confuso." (aluno); "Como posso fazer as respostas se não tem vídeo para conferir ou o que ensine?" (aluna); "Se as atividades fossem de acordo com a explicação que está sendo transmitida iria ajudar bem mais nos estudos" (aluna).

Destacamos, ainda, a fragilidade da comunicação institucional, a precariedade da disseminação de informações cotidianas com relação aos conteúdos e o apoio em caso de dúvidas com relação às aulas, seus componentes curriculares, as atividades indicadas e as dúvidas que delas derivam. Em relação à problemas com o aplicativo e suas funcionalidades, não identificamos, na seção de comentários, respostas frequentes da Prodemge aos usuários do aplicativo. Com relação a SEE, os usuários relatam ter muita dificuldade em obter informações e tirar dúvidas. A maioria absoluta das questões levantadas não têm resposta. Os fragmentos de comentários de alunos que se seguem ilustram esse ponto: "só gostaria que o Prodemge respondesse"; "por telefone não respondem, ou melhor, nem atendem ao telefone".

Em uma situação de emergência, marcada por uma estratégia de formação que é radicalmente diferente daquela historicamente adotada (ainda que temporária), a comunicação é um ponto crucial para que as ações adotadas sejam menos traumáticas. Se os alunos não têm canais eficientes e eficazes para sanar suas dúvidas, como mantê-los motivados e

RIAEE - Revista Ibero-Americana de Estudos em Educação, Araraquara, v. 16, n. 1, p. 84-106, jan./mar. 2021. e-ISSN: 1982-5587 
comprometidos? Se os professores têm demonstrado dificuldades em comunicar-se com seus alunos, como assegurar que o processo de formação não seja tensionado e difícil?

\section{Considerações finais}

Em tempos pandemia, a implementação de ações emergenciais no campo educacional pode aumentar a cobrança por resultados e a responsabilização dos que estão na ponta, especialmente os professores. Dada a complexidade da implementação do REANP, os comentários analisados revelam a dificuldade que a SEE tem enfrentado para criar vínculos e estratégias de adesão multinível entre os atores institucionais, os instrumentos, os processos, as tecnologias, os territórios, os diretores e os professores (que estão trabalhando remota e virtualmente em suas casas). Diante dos desafios, das lacunas e fragilidades institucionais identificadas, o risco de se responsabilizar e culpabilizar os agentes que estão na linha de frente é elevado, já que seu papel é central para assegurar o desempenho dos alunos.

Entretanto, os profissionais da educação também são sujeitos da crise. Se, por um lado, o programa potencializa sua atuação; por outro, agrava as dificuldades que esses atores têm enfrentado ao longo de anos. Como comprar equipamentos mais modernos e aumentar a velocidade da Internet se os salários, em Minas Gerais, são baixos, são pagos em atraso e em parcelas? Como preservar sua vida privada e organizar sua vida pública se a educação remota liquefez tais fronteiras, trazendo a escola, a sala de aula e os alunos literalmente para dentro de suas casas? Como assegurar que se comprometam com o REANP se a comunicação entre a SEE e os profissionais da escola se dá, majoritariamente, por meio de memorandos, fragmentando a informação e criando um clima de insegurança, despreparo e improviso?

Sobre o desenho do programa, há questões importantes que ultrapassam o horizonte da crise. Os comentários revelam que, se para alguns, o ensino remoto é possível; para outros ele resulta no agravamento da desigualdade e exclusão já existentes. Do ponto de vista pedagógico, ainda que o esforço da SEE deva ser reconhecido, os comentários mostram o quanto a Secretaria (e as demais redes) precisa(m) avançar e aprender, especialmente em relação à produção de conteúdo, gestão e integração de plataformas virtuais, comunicação institucional e suporte às dúvidas apresentadas tanto pelos profissionais da escola, quanto pelos alunos e suas famílias.

Questões ligadas ao planejamento visual, à edição, às imagens e recursos gráficos para ilustrar temas tratados pelos professores ganham proeminência nessa modalidade. Cabe destacar o desafio que a SEE e os professores da rede estadual têm enfrentado no desenho 
dessas aulas. Como a imensa maioria não tem intimidade com videoaulas, aspectos associados à didática, dicção, interação e desenvoltura na tela emergem como elementos-chave nesse processo.

Se considerarmos as demandas de grupos específicos, a questão é ainda mais grave. Não foram encontradas ações ou estratégias destinadas aos alunos da educação especial, quilombola, indígena e da educação de jovens e adultos. Os dados analisados sugerem, portanto, que a Secretaria minimizou ou ignorou as especificidades desses alunos (e suas regiões) em seu desenho, linearizando a oferta da educação remota.

Sobre o uso das tecnologias, entendemos que os professores não podem ser o ponto de partida para a análise, isoladamente. Trata-se de uma fragilidade institucional e, também, curricular, vinculada à formação inicial, na educação superior. Como utilizar as Tecnologias Digitais da Informação e Comunicação (TDICs) e operacionalizar seus processos nesses tempos se a SEE não tem diretrizes e programas de formação continuada para que as escolas e seus professores pudessem, muito antes da pandemia, construir estratégias de formação que integrassem tais recursos? Como utilizar tecnologias levando-se em consideração a diversidade de alunos e suas particularidades em relação ao processo formativo? As instituições de educação superior têm tratado e abordado essas questões em seus currículos, nos cursos de formação inicial de professores? Outra questão se impõe, a partir da experiência em curso: a SEE investirá em estratégias dessa natureza quando a pandemia passar?

Em relação aos alunos e suas famílias, Kampen (2020) recomenda que a escola atue em sintonia com as famílias e otimize os meios para atingir os atores envolvidos no processo de ensino remoto. A autora recomenda que a comunicação seja clara o bastante para evitar sobrecarregar os responsáveis, que já estão afetados. Todavia, a comunicação com os familiares dos estudantes também é fundamental. Eles precisam se sentir apoiados para auxiliar os estudantes. Segundo a autora, o engajamento dos estudantes depende do formato do ensino remoto que lhe é oferecido e das condições técnicas para acessar as ferramentas necessárias. Assim, enfatizamos que o aprendizado remoto é diferente do presencial. Ensinar remotamente não é oferecer ao aluno instruções como se ele estivesse no ensino presencial.

Para o caso das redes públicas de ensino, essa tarefa se torna complexa porque há famílias que têm (sérias) limitações para auxiliar os estudantes. Responsáveis que trabalham, que têm pouca escolaridade ou, ainda, precisam apoiar muitas crianças ao mesmo tempo. As condições socioeconômicas e de infraestrutura também são relevantes. Como são geralmente mais pobres e vivem em domicílios menores e mais restritos, educar em casa pode ser uma missão impossível. É preciso garantir que as crianças oriundas dessas famílias tenham acesso 
à todas as orientações necessárias ao bom andamento dos seus estudos, o que, ultrapassa as questões de ordem educacional. A educação pública remota vincula e potencializa questões (e políticas públicas) sociais, culturais e econômicas que estão associadas com um profundo histórico de exclusão e pobreza. É nesse sentido que alertamos para os riscos de a educação remota aprofundar as desigualdades, conforme alertado por Pires (2019).

\section{REFERÊNCIAS}

ALVES, M. T. G.; SOARES, J. F.; XAVIER, F. P. Índice Socioeconômico das Escolas de Educação Básica Brasileiras. Ensaio: aval. pol. públ. Educ., Rio de Janeiro, v. 22, n. 84, p. 671-704, jul./set. 2014.

BRASIL. Instituto Nacional de Estudos e Pesquisas Educacionais Anísio Teixeira. Sinopse Estatística da Educação Básica 2019. Brasília: INEP, 2020. Disponível em: http://inep.gov.br/web/guest/sinopses-estatisticas-da-educacao-basica. Acesso em: 2 jun. 2020.

BRASIL. Parecer CNE/CP n ${ }^{0}$ 5/2020, aprovado em 28 de abril de 2020. Brasília: Conselho Nacional de Educação, 28 abr. 2020. Disponível em: http://portal.mec.gov.br/index.php?option=com_docman\&view=download\&alias $=145011$ pcp005-20\&category_slug=marco-2020-pdf\&Itemid=30192. Acesso em: 2 jun. 2020.

GESTRADO. Grupo de Estudos Sobre Política Educacional e Trabalho Docente. O piso salarial profissional nacional em Minas Gerais: implicações sobre a carreira, a remuneração e representação sindical docente (Fapemig). 2017.

GOMES, R. L. Aspectos da Educação brasileira em meio aos dilemas de um momento dramático. In: LOLE, A.; STAMPA, I.; GOMES, R. L. Para além da quarentena: reflexões sobre crise e pandemia. Rio de Janeiro: MV Serviços e Editora, 2020.

KAMPEN, M. Remote learning: 6 best ways to engage your students (from Teachers!). Disponível em: https://www.prodigygame.com/blog/remote-learning-engagement/. Acesso em: 1 jul. 2020.

LÉVY, P. O que é o virtual? 2. ed. Trad. Paulo Neves. São Paulo: Editora 34, 2011.

MADEIRA, L. et al. Os estudos de políticas públicas em tempos de pandemia. Blog DADOS, 2020. Disponível em: http://dados.iesp.uerj.br/os-estudos-de-politicas-publicas-em-temposde-pandemia/. Acesso em: 2 jun. 2020.

MARTIN, F.; RITZHAUPT, A. D. Standards and competencies: for instructional design and technology professionals. In: MCDONALD, J. K.; WEST, R. E. (Eds.). Design for learning: principles, processes and praxis. 1. ed. EdTech Books, 2020.

MINAS GERAIS. Secretaria de Estado de Educação. Série Histórica da Educação de Minas Gerais 2008/2017. Belo Horizonte: SEE/MG, 2017. 
OLIVEIRA, B. R. A implementação de políticas educacionais no nível micro: uma análise a partir dos profissionais da escola no contexto da prática. Revista de Estudios Teóricos y Epistemológicos en Politica Educativa, v. 4, p. 1-17, 2019.

OLIVEIRA, B. R.; DAROIT, D. Public policy networks and the implementations of the Bolsa-Família Program: an analysis based on the monitoring of school attendance. Archivos Analíticos de Políticas Educativas, v. 28, 2020.

OLIVEIRA, M.; PAES CARVALHO, C. Enfrentando o fracasso escolar no nível local: a atuação discricionária de professores e diretores escolares na implementação de uma política educacional. In: PIRES, R. R. C. Implementando desigualdades: reprodução de desigualdades na implementação de políticas públicas. Rio de Janeiro: Ipea, 2019.

PEREIRA, M. S. F.; SILVA, M. S. P. Educação Básica em Minas Gerais no Contexto da Pandemia e na Trilha do Partido "Novo". Revista Educação Básica em Foco, v. 1, n. 1, abr./jun. 2020.

PIRES, R. R. C. Implementando desigualdades: reprodução de desigualdades na implementação de políticas públicas. Rio de Janeiro: Ipea, 2019.

QUEIROZ, B. L. Diferenciais regionais de salários nas microrregiões mineiras. 2001. 191 f. Dissertação (Mestrado) - Faculdade de Ciências Econômicas, Universidade Federal de Minas Gerais, Belo Horizonte, 2001.

SOUZA, C. "Estado do campo" da pesquisa em políticas públicas no Brasil. Revista Brasileira de Ciências Sociais, v. 18, n. 51, 2003. Disponível em:

http://www.scielo.br/pdf/\%0D/rbcsoc/v18n51/15983.pdf. Acesso em: 3 jun. 2020.

UNESCO. Suspensão das aulas e resposta à COVID-19. Disponível em: https://pt.unesco.org/covid19/educationresponse. Acesso em: 5 jun. 2020.

\section{Como referenciar este artigo}

OLIVEIRA, B. R; OLIVEIRA, A. C. P; JORGE, G. S.; COELHO, J. F. Implementação da Educação Remota em tempos de pandemia: análise da experiência do estado de Minas Gerais. Revista Ibero-Americana de Estudos em Educação, Araraquara, v. 16, n. 1, p. 84-106, jan./mar. 2021. e-ISSN: 1982-5587. DOI: https://doi.org/10.21723/riaee.v16i1.13928

Submetido em: 16/03/2020

Revisões requeridas: 17/07/2020

Aprovado em: 16/10/2020

Publicado em: 02/01/2021 